\title{
Exploring the Transfer of Cultural Specificity in Film Subtitling \\ The Case Study of University Teachers of European Universities
}

\begin{abstract}
:
The basic aim of the present paper is to explore the way cultural specificity is rendered in film subtitling and how it is approached at the academic level. To this end, a questionnaire was administered online to ten teachers of subtitling from different European universities in order to gather direct information about the general issues surrounding this topic and attain a deeper perception of the methodologies followed by professionals in the field together with their ensuing problems and limitations.
\end{abstract}

Key words: Culture, film subtitling, technical procedures, academic education.

$$
\begin{aligned}
& \text { يهذف هذا المقال أساسا الى استكثاف الطريقة } \\
& \text { التي يتم بها تقديم الخصوصية الثقافية في ترجمة }
\end{aligned}
$$

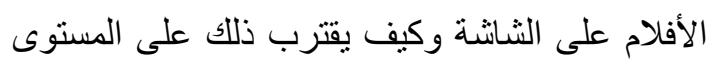

$$
\begin{aligned}
& \text { الأكاديمي. ولهذا فقد تم تسليم استبيان عبر الانترنت } \\
& \text { لعشرة أساتذة ترجمة من جامعات أوروبية مختلفة } \\
& \text { بصدد جمع معلومات مبانرة حول القضايا العامة التي } \\
& \text { تحيط بهذا الموضوع و التوصل الى تصور أعمق حول مئل } \\
& \text { المنهجيات المتبعة من قبل مختصين في المجال } \\
& \text { و الكثف عن المشاكل و القيود التي تترتب عن ذللك. }
\end{aligned}
$$

\section{BENLAHRACHE Wafa Safinez}

Faculty of Letters and Languages

Department of Foreign Languages

University of Mentouri

Constantine

\section{Introduction :}

Two dominant modes of translation have been used in the distribution and consumption of filmic productions worldwide, namely, dubbing and subtitling. Preferences to use one method over the other vary from country to country and are dependent on many factors. Even so, these modes respond to serious challenges, notably concerning their interference with the original content. 
Accordingly, the present paper attempts to provide a clear insight into the way professionals in the field deal with culture as a central element in the understanding and transfer of film dialogue, especially at university level. In a narrower scope, the primary focus of this study is shifted towards subtitling as questions about technical and practical procedures are addressed as well as other educational and professional issues.

\section{Literature Review}

\section{Cross-cultural Awareness and Cultural Transfer through Translation}

Culture and language are intimately related as culture affects both the structure and the functional use of language. This, as a result, automatically influences communication and allows culture to serve as a requisite reference to achieve full grasp when people with shared or disparate cultural backgrounds engage in different kinds of interaction.

Intercultural communication (ICC) is an area of interest in which researchers focus their efforts on studying communication issues that are manifested across cultural boundaries be it intra- or inter-lingual. The general intention of this subject is to help manage successful communication through which behaviours are deemed to be culturally acceptable and appropriate. Its objectives set solid grounds for translators' training; while its problems constitute a significant area of investigation that translation studies aspire to resolve (Robinson, 2007). Added on the relevance of translation to communication, Yanhong (2008) maintained that "translation constitutes an effective means of facilitating crosscultural understanding by bridging the communication gap between the source and target text" (p. 100).

The collision between the latter two prime subjects avers to be incontestably of considerable importance and gains a central focus on the part of different scholars who are in a constant quest for answers and justifications to problems of equivalence and transfer of meaning. According to Robinson (2007), the cultural turn in translation studies rejects the conservative view that there are never any real causes to such problems; but rather aims "to explore the ways in which the various requirements and prohibitions placed on translators are not universals, to be obeyed in all circumstances, but culturally channeled lines of force, often intensely local in their impact" (p.198).

The recent shift in translation studies from linguistic to social and political perspectives is also the result of such controversial matters of faithfulness and accuracy in translation. In addition to the "immediate textual context", an equally important "spatial" context is well-identified and receives enough consideration and emphasis. Chesterman (2006) outlined its main constituents:

- Cultural context: focus on values, ideas, ideologies, traditions, etc.

- Sociological context: focus on people (especially translators), their observable group behaviour, their institutions, etc. 
- Cognitive context: focus on mental processes, decision-making, etc. (p. 11).

From this standpoint, a focus on the process of translating and the conception of its practice is clearly highlighted. The role of the translator as an active agent during this process has a direct impact on the finished product. The translator as a reader and interpreter of the source text's integral meaning is under strict obligation to perform an ethical and responsible rendition of not just the existing sum of knowledge within the original text but also its desired effect on the receiving population. Grosman (1994) emphasised "the fact that no translator can claim impersonal access to the textual meaning, nor is it possible to translate in a social vacuum" (p. 52). This implies that the translator's vision should stem from careful reading and close understanding of cultural specificities. Put differently, the translator should acquire an adequate amount of cultural awareness to attain his ambitious goals.

Acknowledgment of the magnitude and depth of cultural differences enhances awareness of the meanings associated with copious cultural constructions which according to Grosman (1994) "can prevent the automatic tendency to perceive the other and the different in terms of the known and the familiar, whereby foreign texts are divested of their very otherness" (p. 51). A good case in point concerns the translation of filmic products as important carriers of culture. In fact, the cultural challenge that the audiovisual field is facing generated a lot of research on how to preserve the originality of the works and prevent some cultures from being dominated by others in order to promote cultural exchange among diverse societies.

\section{Research Design \\ Participants}

Ten university teachers of subtitling took part in the study at hand. All the teachers practise their profession at European universities where majors in subtitling or audiovisual translation are mostly provided. The reason behind choosing them to form the sample of our analysis is the increasing academisation of audiovisual translation which, by consequence, raised the number of professionals who hold an academic degree in subtitling. The methods these subtitlers will apply are, then, the same they have learnt at university from their teachers who are well aware about the recent developments in the field of research. Thus, they necessarily make reliable references with the amount of knowledge and experience they have acquired over time.

\section{Data Collection}

A questionnaire was administered to the teachers in order to meet the research objectives and obtain the largest amount of information possible about different issues regarding the transfer of culture specificity in subtitling and the way such an issue is approached by the teachers during their academic 
trainings. It is composed of eighteen questions and divided into two main sections. The first attempts to gather personal information about teachers' qualifications and work experience; while the second is more concerned with subtitler professional requirements, practical procedures and surrounding topics to the general theme of investigation. All the questions serve the primary objectives of the study and are interrelated and complement one another.

\section{Procedure}

The questionnaire is an online survey that was designed via "Google Docs". The latter is a web-based application that enables full access to the document from any geographical location through the use of a computer device with an internet connection and a fully-featured web browser. The teachers could easily respond to the questions and the data were automatically saved and organised online, whereas the owner of the document is allowed to control and view updates at any time.

It was through a thorough search on the Internet that an e-mail contacts list was created. The list included teacher's e-mails retrieved mostly from the official websites of universities that offered a subtitling major, generally across European countries, or the contacts of the programme leader and the administration as well as associations such as ESIST (European Association for Studies in Screen Translation). Afterwards, a request to fill in the questionnaire was sent to each one on the list. Some of them promised to send the request to other colleagues. The returns took about one month. The data analysis consists of percentage calculations, descriptions and interpretations of the results.

\section{Results and Discussion}

\section{Personal Information: Questions 1, 2, 3, 4 and 5:}

The respondents are teachers from Universitat Jaume 1 (Spain), University of Valladolid (Spain), University of Leeds (UK), University College London (UK), Stockholm University (UK) and Université Nice Sophia Antipolis (France). They are all university awards: They all hold BA and MA degrees, in addition to a $\mathrm{PhD}$ degree for six of them. Six teachers majored in "Audiovisual Translation" and the rest in "Translation". $80 \%$ of the respondents accounted for a work experience that is equivalent to ten years or more; and another $80 \%$ have reportedly worked at a subtitling company for a period that amounts to ten years or more for half of them. As a result, these teachers can be perceived as reliable referents to this study.

Question 6: Into what language combination(s) do you train to subtitle?

This question reveals the different language combinations that are used in the subtitling programmes provided by the aforementioned universities. The source languages the teachers have been translating from are: English, Italian, Spanish and Catalan. In opposition, the list of the target languages comprises English, Spanish, Catalan, French, Swedish and a number of other languages. Given the geographical location of the universities, it is assumed that the languages that 
the teachers use in their training programmes are likely to be their native languages, in addition to second or foreign languages with which they are best acquainted.

\section{Question 7: Which of the following is the mother tongue of the teacher?}

In relation to the preceding question, this one seeks to check in numbers whether teachers use their native languages in their subtitling instructions in order to sustain such views. To Newmark (1988), translating into the language of habitual use is "the only way [to] translate naturally, accurately and with maximum effectiveness" (p. 3). Table 1 below shows the results.

Table 1. Frequency of Teachers' Native Language Use in Subtitling Training

\begin{tabular}{|l|c|}
\hline Option & Percentage \\
\hline Source Language & $30 \%$ \\
\hline Target Language & $40 \%$ \\
\hline None of them & $30 \%$ \\
\hline
\end{tabular}

Between source and target language, $70 \%$ of the respondents use their native languages during their teaching of subtitling in contrast to $30 \%$ whose native languages are none of them. This means that a full mastery of the languages of translation is a prerequisite for the subtitler, in general, especially if one of them is their mother tongue.

Question 8: How do you evaluate your mastery of both Source and Target cultures?

This question received a positive feedback from most of the teachers $(80 \%)$ who confirm a very good mastery of the target culture and a good mastery for the rest $(20 \%)$. For the source culture, $50 \%$ of the teachers posit their understanding to be very good, $40 \%$ are good and only $1 \%$ finds it average. Clearly, the teachers are proficient in the languages they use and, consequently, their cultures. The fact that $70 \%$ of them are using their mother tongues (see Question 7) serves as a plausible explanation to the obtained results. The results are represented in the following figures: 


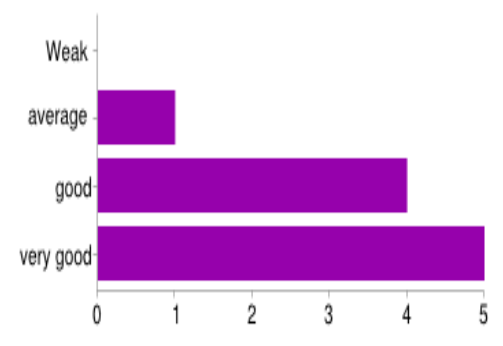

Figure 1. Teachers' Mastery of SC. Mastery of TC.

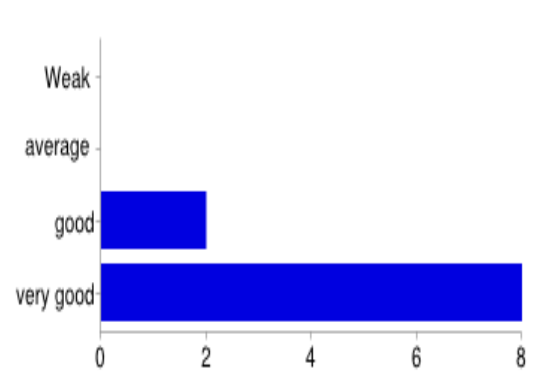

Figure 2. Teachers,

\section{Question 9: How would you define the concept of 'culture'?}

This question investigates teachers' perception of the concept of culture. It provides two definitions to choose from with the possibility to present their own in a third option. The first definition embraces a sociological perspective. It describes culture as a way of life and a system of knowledge that a particular group of people share and pass on to future generations. The second definition, however, focuses on all the aesthetic and intellectual features that characterise the concept of culture as well as its strong connection with civilisation. The following results were obtained (Table 2).

Table 2. Teachers' Definition of the Concept of 'Culture'

\begin{tabular}{|l|c|}
\hline Teachers' definition & Percentage \\
\hline $\begin{array}{l}\text { a. The sum total of the learned behaviours of a people which are } \\
\text { transmitted from generation to generation, which are generally } \\
\text { considered to constitute their tradition, and which serve them as } \\
\text { potential guides for action. }\end{array}$ & $20 \%$ \\
\hline $\begin{array}{l}\text { b. The totality of intellectual products, artistic achievements and } \\
\text { the general mode of human refinement that is associated with } \\
\text { civilisation. }\end{array}$ & $20 \%$ \\
\hline c. Both & $40 \%$ \\
\hline d. Other (please specify). & $20 \%$ \\
\hline
\end{tabular}

The results demonstrate that $60 \%$ of the teachers see that culture signifies both of the suggested definitions and much more, as $20 \%$ chose option (d.) and one of them provided the following details:

"To be culturally literate is to possess the basic information needed to thrive in the modern world. The breadth of that information is great, extending over the major domains of human activity from sports to science. It is by no means 
confined to "culture" narrowly understood as an acquaintance with the arts. Nor it is confined to one social class".

This indicates that the teachers are not oblivious to the varying meanings the term holds, and adequately understand its prevalence in different existing domains. Nonetheless, the remaining $40 \%$ chose only one of the proposed definitions as $20 \%$ were keen on (a.) and another $20 \%$ preferred (b.). Definition (a.) may have represented to them the observable facts of their dayto-day life, while (b.) may have been identified in accordance with its significance to their profession as trainers and university educators.

Question 10: How is culture significant to your training programme?

This question examines to what extent culture is relevant to the teaching of subtitling at European universities. As presented in Table 3, the responses show that culture is $40 \%$ highly significant and $30 \%$ significant to the majority of the training programmes, while $30 \%$ insignificant to some others. Hence, the importance of culture can easily be noticed as it is thoroughly and consciously integrated in the curriculums taught by most of the teachers. The $30 \%$ insignificance of culture is possibly due to the nature of the modules they teach which must provide main concern to different subjects other than culture.

Table 3. Degree of Culture Significance in the Training Programmes

\begin{tabular}{|r|c|}
\hline Degree of Significance & Percentage \\
\hline a. $\quad$ Very Significant & $40 \%$ \\
\hline b. Significant & $30 \%$ \\
\hline c. Insignificant & $30 \%$ \\
\hline
\end{tabular}

Question 11: If you selected (a) or (b), how do you approach the teaching of culture in your lectures? (If you tick "Other", please specify)

In complement to the preceding question, this one aims to gather further information concerning the teaching approaches of culture, based on teachers' personal experience. The $70 \%$ teachers who consider culture significant or very significant in their training programmes were requested to choose from the proposed options the ones with which they identify the most, or specify in their own words any other method they might be using in an open-end to the question (so as to get a fuller response).

To note, each of the four options provided presents a different outlook of culture. In the first, focus is shifted towards the artistic achievements of literature and all what it may characterise as high culture with disregard to any other constituent aspects. In the second, information about historical developments and public organisations of a given community are presented to the learners who remain unaware of the societal rules and customs that govern 
the behaviours and beliefs of the members of a certain community. The latter specification is, thus, offered in a third option. Last of all, the fourth option involves a description of culture as a means of communication and a useful guide to attain a successful interaction between people with different cultural backgrounds. Table 4 displays the proposed selections together with the analysis of the results.

Table 4. Teaching Approaches of Culture

\begin{tabular}{|l|c|}
\hline Teaching approach & Percentage \\
\hline a. Teaching culture through the target language literature & $00 \%$ \\
\hline $\begin{array}{l}\text { b. By providing a body of knowledge about the history, } \\
\text { geography and institutions of the target language }\end{array}$ & $10 \%$ \\
\hline $\begin{array}{l}\text { c. Focusing on culture as shared behaviours and values among } \\
\text { target language members }\end{array}$ & $20 \%$ \\
\hline $\begin{array}{l}\text { d. Culture as a set of practices and a necessary tool of } \\
\text { communication }\end{array}$ & $20 \%$ \\
\hline Other & $20 \%$ \\
\hline
\end{tabular}

$50 \%$ of the teachers' answers were divided between options (b), (c) and (d) with $10 \%$ for (b) and $20 \%$ for each of (c) and (d). Option (a) received no regard; the reason could be due to the fact that literature does not give an inclusive understanding of culture that may be of effective use to the study of subtitling in particular. Culture as a set of distinctive values and behaviours and an essential means of communication constitutes, however, the main highlights in the teachers' approaches. Nonetheless, $20 \%$ of the teachers did not adopt any of the proposed approaches and described their own:

$>$ "Provide examples from literature and practice, ask students to make presentations about their cultures, involve in our teaching practitioners with a variety of linguistic and cultural backgrounds."

$>$ "By making students aware of the distance existing between source/target social realities (language and culture)."

The answers to this question evidence that no exact approach gains everyone's acceptance as almost each teacher favours a separate one. Yet, it is obvious that culture is given careful consideration in the training programmes with teachers finding different ways to implement it from their own perspectives depending on the varying aspects they intend to point out.

Question 12: In film subtitling, how do you describe the impact of proper cultural transfer (including extra-linguistic cultural references) on the appreciation of a film? 
In a special focus on film subtitling, this question is intended to explicate the extent to which cultural specificity is important in the understanding of a film as well as the role it plays in its appraisement if appropriate transfer into other languages and cultures takes place.

Teachers' opinions were accordingly derived from a three-point scale of slight, moderate and strong. The totality of the responses confirms that the impact of proper cultural transfer on the appreciation of a film is $100 \%$ strong. Culture can, hence, be concluded to have a major influence on the good reception of films from audiences with mixed cultural backgrounds and, therefore, necessitates a great deal of attention and care in order to ensure an accurate transmission of its messages.

\section{Question 13: Which method do you think is more recommended in film subtitling?}

In respect to the degree to which film subtitles conform to the target culture or retain source text information to preserve original meaning, this question directly inquires about which method of translation subtitling professionals are inclined to use. The contrasting methods of domestication and foreignisation (Venuti, 1995) were proposed to the teachers to see whether they favour a target language oriented translation, i.e. "domestication" or a source language oriented one, i.e. "foreignisation". Additionally, teachers were requested, in a second part to the question, to justify the motives behind choosing to employ one method over another. Percentage calculations of the results are found in Table 5 .

Table5. Recommended Method in Film Subtitling

\begin{tabular}{|l|c|}
\hline Method & Percentage \\
\hline Foreignisation (SL oriented translation) & $40 \%$ \\
\hline Domestication (TL oriented translation) & $20 \%$ \\
\hline None of them & $40 \%$ \\
\hline
\end{tabular}

From the previous results, teachers' responses can be said to be divided into three disparate standpoints. Domestication gains the lowest percentage rate of $20 \%$ as compared to foreignisation and the neutral position with $40 \%$ for each.

The conflicting views were spelled out by the proponents of the foreignisation method $(40 \%)$ to have different reasons that mainly centre around the distance existing between source and target cultures. According to them, foreignisation is a way of enabling spectators to learn more about source language and culture since they are directly subject to the original version and can simply make observations and draw comparisons about different aspects of the film. Familiarity with source language and culture also makes it easier to follow this method because the meanings can pass through straightforwardly. 
At the same time, if the target audience is unacquainted with source information and the subtitler opts for an equivalence of effect in a persistent target language oriented translation, differences between source and target text can attract viewers' attention and cause the subtitles to be undervalued through what is labelled "the feedback-effect from the original" Gottlieb (1994).

On the other hand, advocates of the domestication method (20\%) set out the reasons to be mostly technical. According to them, the nature of the audiovisual text obliges a quick and effective reproduction of the desired effect of the original, mainly the one that they can readily identify with, without needing to provide further descriptions.

The teachers who sat on the fence (40\%), found it hard to generalise or take a definite side as many factors come into play when it comes to choosing the most appropriate method of translation. Distance between source and target cultures, film genre, target language and scene are among such factors. The teachers advance that these two methods cannot be standardised because although they are necessary in many instances, they can in much the same way distort the authenticity of the audiovisual material given that it is subjugated to different kinds of constraints.

To sum up, the responses did not provide a clear-cut recommendation as to which method of translation is better fit in the film subtitling. The latter is conditioned by many aspects that seem to influence the subtitler's decisionmaking. As stated above, distance between source and target cultures is an essential element to be taken into consideration because the subtitles tend to be more inconsistent when the gap between them widens. Therefore, the reason why foreignisation gained a higher percentage in contrast to domestication in this survey can be due to the close resemblance source and target cultures bear as the teachers are all from European countries and use Germanic language combinations in their subtitling trainings. Still, other factors such as film type and the technical and contextual constraints within a scene might as well crucially affect the process of subtitling and the general rendition of the original text.

Question 14: What strategy(s) is/are adopted when dealing with culturespecific references in film subtitling? (If you tick "Other", please specify)

Culture-specific references are specially dealt with in film subtitling using multiple strategies. Although different labels and classifications can be found, the question was backed up by a list of strategies that are mainly used in this particular context (Tomaszkiewicz, 1993) to see which of these strategies is more commonly employed and considered the most effective by the subtitling instructors. The strategies provided are namely enlisted in Table 6 together with the calculated percentages of their use. 
Table 6. Strategy Used when Dealing with Culture-Specific References in Film Subtitling

\begin{tabular}{|l|c|}
\hline Strategy & Frenquency of use \\
\hline a. Omission & $20 \%$ \\
\hline b. Literal Translation & $10 \%$ \\
\hline c. Borrowing & $10 \%$ \\
\hline d. Equivalence & $20 \%$ \\
\hline e. Adaptation & $40 \%$ \\
\hline f. Replacement of the cultural term with deictics & $10 \%$ \\
\hline g. Generalisation & $40 \%$ \\
\hline h. Explication & $40 \%$ \\
\hline i. All of them & $30 \%$ \\
\hline Other & $10 \%$ \\
\hline
\end{tabular}

From the table, no strategy was excluded as all of them were selected even though at varying percentages. $30 \%$ saw that all strategies are used when dealing with culture-specific references, while one response appended that the choice depended on many factors. 'Adaptation', 'generalisation' and 'explication' got each the highest percentage rate of $40 \%$. Although they might somehow alter or add up to the original meaning, they appear to be the most frequently used as they allow a better understanding of such cultural connotations for the target audience. Next, with a percentage of $20 \%$, 'omission' is also adopted by the subtitlers who would rather prefer to discard certain cultural elements than risk a failed interpretation. Conversely, 'equivalence' is equally seen to be more appropriate when these elements match up with their corresponding counterparts in the target culture. Last, the lowest percentage of $10 \%$ was attributed to all of 'literal translation', 'borrowing', and 'Replacement of the cultural term with deictics' as they seem less recurrent and variable.

Question 15: Do these reasons influence the choice of certain strategies? (If you tick "Other", please elaborate)

This question aims to identify the prevailing reasons that characterise the choice of the previously mentioned strategies. The transfer of culturespecific elements in films takes a special dimension as it is certainly governed by a variety of conditions that might not only include genre and technical restrictions; but also extra-textual and industrial interferences. Basic instances 
of such conditions are delineated in the table below along with the teachers' responses.

Table 7. Reasons Influencing the Choice of Certain Strategies

\begin{tabular}{|l|c|}
\hline Reason & Percentage \\
\hline a. The type of the cultural reference itself & $40 \%$ \\
\hline b. Degree of distance between cultures & $50 \%$ \\
\hline c. The targeted audience (categories of viewers) & $40 \%$ \\
\hline d. The type of film & $50 \%$ \\
\hline e. Technical interferences & $20 \%$ \\
\hline f. Motivation on the part of the subtitler & $00 \%$ \\
\hline g. Subtitling norms & $40 \%$ \\
\hline h. Budget & $10 \%$ \\
\hline i. Deadlines & $20 \%$ \\
\hline j. All of them & $50 \%$ \\
\hline Other & $0 \%$ \\
\hline
\end{tabular}

Clearly, most suggestions received high acclamations from the teachers as exactly one-half approved of all of them. The second half also gave full consent to suggestions (b.) and (d.); and $40 \%$ to (a.), (c.) and (g.); thus, making 'the degree of distance between cultures', 'the type of film', 'the type of the cultural reference itself', 'the targeted audience', and 'subtitling norms' the top factors that might definitely influence the subtitler's strategic choices regarding cultural items. Lower rates were determined by the second part of the teachers for 'technical inferences', 'budget' and 'deadlines' in addition to $0 \%$ for 'motivation of the subtitler' which indicates that they hold a slightly less important impact as compared to the aforementioned causes. Again, what the subtitler might consider most are all the distinctive features that primarily pertain to the culture-specific element itself, such as film type and the level of difference and acceptability from audience. Financial and professional conditions take a secondary position in a list where all options are relevant. No hint to further suggestions was put forward.

Question 16: According to you, what factors can affect the quality of subtitles? (If you tick "Other", please elaborate)

Many factors can contribute to the assessment of the quality of subtitles. Three inclusive factors were proposed in this survey, namely, "cultural", "technological" and "professional" in order to comparatively 
evaluate the degree of influence culture can have on subtitle quality. As put in the previous discussions, culture is directly linked to semantic coherence in that discrepancy in meaning and failure of translation can result from its recurrent misinterpretation. Moreover, cultural factors include context-related issues that vary between audiovisual variables (ex. textual features) and sociological variables (E.g. Categories of viewers). The technological factors are also worth citing since technological developments have undeniably affected the field of Audiovisual Translation and served the needs of different groups of recipients (E.g. the hearing impaired). Professional factors, with specific reference to the subtitler's abilities, form another explicative facet to the issue of quality in subtitle delivery given that cultural and technological factors cannot be accounted for without the subtitler's righteous manipulation and complete mastery of the latter.

Table 8. Factors Affecting the Quality of Subtitles

\begin{tabular}{|l|c|}
\hline Factor & Percentage \\
\hline Cultural & $60 \%$ \\
\hline Technological & $80 \%$ \\
\hline Professional ( subtitler's skillfulness) & $80 \%$ \\
\hline Other & $10 \%$ \\
\hline
\end{tabular}

Table 8 shows that all proposed options can clearly affect the quality of subtitles, especially technological and professional factors which gained the confirmation of $80 \%$ of the teachers. In addition, with a lower percentage of $60 \%$, the cultural factor may also have a direct impact on the quality of subtitles. Nonetheless, one response puts forward commercial factors which involve budgetary and time constraints.

Question 17: Do you think that an academic degree in subtitling is necessary to produce high quality subtitles?

In recent years, the incorporation of subtitling as a new discipline in higher education has gradually taken place, especially in European countries. The overwhelming technological developments gave way to an increased trade of all kinds of audiovisual products all over the world which, consequently, dictated different forms of translation. This implies that, in order to keep up with those advances and come up with better results, the audiovisual industry requires the services of professional subtitlers who are apt to master all technical and linguistic skills and are well-informed about the working conditions and regulations. Thus, it is sought throughout this question to find out whether the acquisition of an academic degree in subtitling can meet those requirements and enhance the quality of subtitles. 
The obtained results show that $80 \%$ of the teachers agree that a university degree in subtitling is more appreciated when it comes to producing a satisfactory outcome. Considering that $80 \%$ of the respondents have had a working experience at a subtitling company that rose up to more than a decade for some of them, it is possible to deduce that their evaluation is based on profound knowledge and thorough analysis of the situation.

Question 18: Are you pedagogically satisfied with the teaching of culture in university?

In view of the importance of culture in language and translation studies, the concept is assumed to have earned a right place in university and gained proper consideration within the variety of disciplines available. With a special focus on audiovisual translation, it is intended throughout this question to gather factual information on this issue and analyse its pros and cons in accordance with teachers' opinions as reliable experts in the field.

The results are given in two equal proportions. $50 \%$ of the teachers were satisfied with the amount of involvement culture gets in the teaching programmes at their universities; whereas the second half provided negative replies.

The results were given multiple explanations. On the whole, teachers who expressed their contentment with the methods they are applying in the teaching of culture seemed very confident about what they opted for. They expounded that it is mainly based on collaborations with colleagues from other departments and freelance translators who have experience in dealing with this topic both from a research viewpoint and from a practical perspective.

On the other hand, teachers complained about the lack of proper consideration for the teaching of culture at their universities because the syllabuses are designed in a way that gives higher priority to other specialised modules, such as translation norms and technical issues, which take most of their time. As a consequence, not enough culture is taught and it is left in some universities to non compulsory courses. Other arguments questioned the effectiveness of course contents in the future professional practice. Besides, they criticised constant modifications and educational regulations which have an undesired outcome on the cultural background of students who may unintentionally reject their home culture to foreign cultures through regular exposure to audiovisual products.

\section{Conclusion}

In a serious attempt to explore the basic aspects influencing the transfer of cultural specificity in film subtitling, a number of conclusions could be drawn based on the obtained results. First of all, the role the concept of culture plays in the understanding and appreciation of films is definitely very 
significant because it directly interferes in the subtitling process and has a strong impact on subtitle quality.

In addition, academic education of subtitling and collaboration among professionals is widely encouraged in order to promote awareness about professional reality and enable the subtitlers to properly evaluate both the linguistic appropriateness and cultural sensitivity of each film dialogue they intend to translate. Subtitlers are not only required to fully master the languages and their cultures, but also all the technical procedures associated with the transfer of culture-specific elements. There is absolutely no clear guideline as to which procedure must be used because the choice is motivated by a variety of reasons that may include extra dimensions than just the textual and technical ones. Different variables should be analysed in order to come up with the most suitable translation bearing in mind that the importance attributed to them varies from one country to another and from one film to another.

\section{References}

Chesterman, A. (2006). Questions in the sociology of translation. In J. F. Duarte \& A. A. Rosa \& T. Seruya (Eds.), Translation studies at the interface of disciplines (pp. 9-28). Philadelphia: John Benjamins Publishing Co.

Gottlieb, H. (1994). Subtitling: people translating people. In C. Dollerup \& A. Lindegaard (Eds.), Teaching Translation and Interpreting (pp. 261-274). Amsterdam:John Benjamins.

Grosman, M. (1994). Cross-cultural awareness: focusing on otherness. In C. Dollerup, A. Lindegaard \& A. Lindegaard (Eds.), Teaching translation and interpreting 2: Insights, aims, visions (pp. 51-58). Amesterdam: John Benjamins Publishing Co.

Newmark, P. (1988). A textbook of translation. London: Prentice Hall.

Robinson, D. (2007). Becoming a translator: An introduction to the theory and practice of translation ( $\left.2^{\text {nd }} e d.\right)$. London: Routledge.

Tomaszkiewicz, T. (1993). Les opérations linguistiques qui sous-tendent le processus de sous-titrage des films. Poznan: Adam Mickiewicz University Press.

Venuti, L. (1995). The translator's invisibility: A history of translation. London:

Routledge.

Yanhong, X. (2008). Towards pluralistic and interdisciplinary approaches: A reflection on translation studies in contemporary China. In W. Ning \& S. Yifeng (Eds.), Translation, globalisation and localisation: A Chinese perspective (pp. 88-107). Clevedon: Multilingual Matters Ltd. 